\title{
Notas sobre amizade e familia: a vida como obra de arte no encontro com Antônia e as cinzas no jardim*
}

Elizabete Franco Cruz ${ }^{*}$

DOI: $10.1590 / 0103-7307201607905$

\section{Resumo}

0 artigo apresenta uma reflexão sobre amizade e família a partir do filme Excêntrica família de Antônia e do pedido feito por um participante de uma ONG AIDS antes de seu falecimento. Utilizando ferramentas conceituais de Michael Foucault e de autoras e autores que dialogam com a obra do autor, o texto interpela o lugar da diferença nas famílias e a centralidade da família como referência do contexto social. 0 debate sobre amizade remete à dimensão política do espaço público e à possibilidade de invenção de modos coletivos de vivência, levando a novas configurações da ética e da estética da existência dos indivíduos e da sociedade.

Palavras-chave: amizade, família, AIDS

* Dedico este texto aos meus amigos e amigas, em especial os participantes do Grupo de Incentivo à Vida e do Movimento Brasileiro de Luta contra AIDS.

** Escola de Artes, Ciências e Humanidades, Universidade Estadual de São Paulo - USP, São Paulo, SP.betefranco@usp.br 


\title{
Notes on friendship and family: life as a work of art in the meeting with Antonia and the ashes in the garden
}

\begin{abstract}
The paper presents a discussion on friendship and family based on the movie Antonia's Line and on the request made by a AIDS NGO participant before his death. Using conceptual tools of Michael Foucault and other authors who engage in conversations with his work, the text questions the place of difference in families and the centrality of family as reference of social context. The debate about friendship refers to the political dimension of public space and the possibility of inventing collective ways of living, leading to new configurations of ethics and aesthetics of existence of individuals and society.
\end{abstract}

Keywords: friendship, family, AIDS 
A proposta deste artigo é desenhar algumas notas sobre família e amizade, utilizando como mote duas experiências que me tocaram profundamente: um dos últimos pedidos de um amigo que faleceu em decorrência da AIDS e o filme Excêntrica família de Antônia.

Para alcançar o objetivo do trabalho, organizei o texto da seguinte maneira: inicio com uma breve síntese do filme e da história do meu amigo e posteriormente partilho as inquietações que dialogam com essas duas experiências e com as ferramentas conceituais de Foucault e de autores que utilizam a obra do filósofo francês.

\section{A excêntrica familia de Antônia}

O filme é uma produção do Reino Unido, da Bélgica e da Holanda e narra a vida de Antônia. No começo da narrativa, Antônia volta para sua cidade natal, junto com a filha Danielle, para acompanhar o falecimento e o enterro da mãe. A partir de sua chegada, Antônia reorganiza a vida e interfere na comunidade em que vive, porque agrega ao redor de si um conjunto de pessoas que, por diferentes razões, não se enquadram nos modos hegemônicos de vida do vilarejo. Fazem parte do universo de Antônia uma mulher que uiva, um velho intelectual e solitário, um deficiente mental, uma jovem estuprada pelo irmão, um viúvo com vários filhos, uma mulher que tem muitos filhos (por gosto e opção) e um padre que abandona a batina.

Danielle, filha de Antonia, decide ter um filho, e Antônia a auxilia, buscando um homem para a reprodução. Letta, a mulher que gosta de engravidar, as ajuda. Posteriormente, Daniele assume sua homossexualidade e se apaixona pela professora de Therese, sua filha, que cresce com a avó - duas mulheres em forte convivência com um intelectual, o velho Dedo Torto. Na trilha geracional, Therese tem uma filha chamada Sara, que, no filme, é a narradora da vida de Antônia.

Dentre vários assuntos polêmicos, o filme aborda o estupro e o aborto. No caso do estupro, uma grande interpelação deixada pela história é a possibilidade que Antônia tem, e não utiliza, de matar o homem que violentou sua neta. No caso do aborto, observamos um debate aberto, envolvendo toda a família, que opina sobre a decisão de Therese dar ou não continuidade a uma gestação. E isso acontece de modo "natural”, com a participação das crianças.

Em síntese, o filme mostra a vida de uma mulher que, além de uma linhagem biológica, articulou ao redor de sua vida pessoas marginalizadas e desenhou modos de existência que manejam temas polêmicos (aborto, estupro, homossexualidade, abandono, sexualidade) de modo criativo, livre e inovador. 


\section{Cinzas no jardim}

Há muitos anos vivo no espaço por alguns denominado de "mundo da AIDS" (convivendo com ONG, serviços de saúde, pessoas, políticas e pesquisas). Em diferentes planos (vida pessoal, profissional ou ativismo), já vivi, senti, presenciei, observei inúmeras situações, demandas, desafios, experiências.

Uma dessas experiências vividas por volta de 2005, interpelou-me de maneira profundamente triste e, ao mesmo tempo, profundamente bela e reveladora. Sou associada de uma ONG denominada Grupo de Incentivo à Vida - GIV - e, na época, tinha um intenso e cotidiano envolvimento com várias pessoas da instituição.

Um companheiro nosso, T., faleceu, e, pela sua centralidade em nossas vidas e no trabalho, vivemos dolorosamente o impacto dessa perda. Antes de sua morte, ele fez três pedidos: ser cremado, não usar paletó no caixão e, por fim, que suas cinzas fossem colocadas no jardim do GIV. Todos os seus pedidos foram atendidos.

\section{A existência e seu fim-começo ou a dança que dançamos}

Nada morre para sempre, alguma coisa sempre fica de onde outra nasce. Assim a vida começa sem saber de onde veio, ou por que existe. Porque a vida quer viver. Esta é a única dança que dançamos.

(do filme Excêntrica família de Antônia)

Nas duas histórias dialogamos com a morte: Antonia morre. 0 meu amigo T. morre. $\mathrm{E}$ as mortes deixam as perguntas a respeito do que eles fizeram com a vida. Nos casos que aqui debatemos, as vidas são marcadas por uma estética da existência que inclui a diferença, que acolhe e ampara a diferença, convive e lida com ela. São vidas que, a meu ver, dançam por aquilo que Foucault nomeou como amizade.

Diz a narrativa cinematográfica: a vida quer viver. Contudo, como a vida quer viver?

Examinemos com um pouco mais de vagar estas duas vidas - a da ficção e a da realidade.

T. e Antonia pensaram e prepararam sua morte. Ele, porque tinha AIDS e adoeceu. Ela, porque envelheceu. E o filme parece querer nos convidar a pensar no tempo finito

1. Para uma reflexão a respeito da morte, podem interessar: Ariès (2003); Bromberg, Kovács, CarvaIho, \& Carvalho (1996); Elias (2001); Giacóia Junior (2005); Kóvacs (1992); Kübler-Ross (1998). da vida. Por isso, a morte também está presente neste texto. Não vou explorar o debate teórico a esse respeito ${ }^{1}$, mas sinalizo que, ao falar da vida 
como obra de arte, ao pensar na ética e na estética da existência, é importante pensar no que o filme e a experiência com T. nos permitem refletir: a vida é finita e há que pensar o que fazemos com ela.

T. pede para jogar suas cinzas no jardim do GIV. Há anos quis escrever sobre isso, mas precisei aguardar o tempo, a possibilidade (interna e externa).

$\mathrm{Na}$ época, fiz alguns registros e lembro que minha primeira reação foi de profundo incômodo: meu maior medo era de que outros amigos pudessem resolver fazer a mesma escolha. E teríamos um jardim cheio de amigos-cinzas ou cinzas de amigos.

No impacto da dor, muitas questões me assombravam. Como posso viver com isso? Como posso viver com a imagem de T. olhando pela janela? E, agora, quando olho para a janela, ele não está. Nem nas salas em que trabalhávamos e, paradoxalmente, nem no jardim. E ficamos com este vazio profundo. Somente preenchido com a sua presença dentro de nós. Certamente sabemos que, em nosso mundo psíquico, as pessoas não desaparecem, ficam na memória. T., na minha e de nossos amigos; Antonia, no relato de sua neta.

Nós, que somos tecidos por palavras em vida (Larrosa-Bondía, 2002), com os nomes que herdamos no nascimento, com os adjetivos que nos qualificam na existência, após nossa morte permanecemos como palavra na narrativa de alguns que conosco partilharam o existir ou nos registros que deixamos ou que deixam sobre nós. Também nos metamorfoseamos em ossos e cinzas.

Contudo, continuemos. T. pede para permanecer no jardim e entristecemos. Que estranha sensação: ter alguém que você ama (no caso, um amigo) e saber que, na materialidade da existência, tudo o que restou dele foram cinzas que a chuva misturou com terra do jardim. Como pensar que aquele que abraçamos, de quem sentimos o calor, hoje é apenas terra no jardim?

Isto sempre acontece: nossos corpos se extinguem. Entretanto, a presença no jardim é o ponto inquietante da história. Ele queria permanecer ali. E por quê? Não houve tempo, antes de sua morte, para pensarmos o sentido que atribuiu a essa escolha. A busca desse sentido ficou como tarefa para nós, que permanecemos vivos.

Afinal, por que ele escolheu justamente o jardim do GIV? Por que não Nova Iorque, Torre Eiffel, Tâmisa, o oceano, alguma linda praia do Nordeste? Por que um pequeno e singelo jardim de uma casa velha na Vila Mariana?

Imaginamos que, simbolicamente, ele queria continuar conosco. Permanecer no lugar que ajudou a construir, no lugar que the serviu de referência e no qual foi refe- 
rência para tantas pessoas.

Vale lembrar que T. não era ativista conhecido nacionalmente, não falava em mesas, nem ocupava representações. E, mesmo assim, nessa posição que alguns imaginam menor, foi fundamental na luta contra a AIDS.

Do seu modo, participou de muitas iniciativas importantes. Contribuiu para o surgimento do grupo de adesão do Centro de Referência e Treinamento em DST AIDS de São Paulo e, ao se referir aos medicamentos antirretrovirais, cunhou a frase que virou nome de livro: “Tá difícil de engolir!” (Teixeira, Paiva, \& Shimma, 2000).

Além disso, foi um dos membros do início do GIV, e, em síntese, podemos dizer que, entre tantas questões, tinha três grandes "bandeiras": a adesão aos medicamentos; a luta contra o estigma e a discriminação; e o cuidado. Ele era um dos grandes cuidadores do GIV e das pessoas do GIV.

Escolher deixar suas cinzas em nosso jardim não foi por desconhecimento de tantos lugares importantes, nobres e belos. Ao contrário, possivelmente, foi um modo de dizer como era importante para ele o que o GIV representa. Não a casa velha e o jardim do tamanho de um tapete, mas o espírito de solidariedade, amizade e valorização da vida que norteia a existência da ONG, que se engendrou visceralmente nas falas: "Você não está sozinho" e "Pessoas vivendo com HIV AIDS como sujeitos de suas histórias?”.

A partir dessa experiência, cabe pensar o que significa fazer parte do movimento brasileiro de luta contra a AIDS? Sim, porque, com certeza, constituir um lugar que confere sentido à vida não se restringe ao GIV. Inúmeras outras ONG, na cidade, no estado e no Brasil ocupam esse lugar de referência, de pertencimento. O que então estamos produzindo, inventando, desenhando em nossa sociedade?

Arrisco neste texto uma resposta para essa questão: mais do que cuidado e fortalecimento para pessoas que são afetadas por uma epidemia, no interior das organizações sociais de luta contra AIDS é possível vislumbrar formas de socialização que se contrapõem a um modelo hegemônico de relacionamento fundado no biopoder ${ }^{2}$, formas de socialização pautadas na amizade.

\footnotetext{
2. 0 conceito de biopoder aparece ligado ao controle sobre a vida e a morte (políticas de vida biológica, morte associada ao racismo). Diz respeito ao papel do Estado no controle das populações e também ao papel dos saberes na vida dos indivíduos. A esse respeito, ver Castro (2009) e Foucault $(1999,2003)$.
}

Podemos lembrar que nosso amigo era solteiro, homossexual, portador de HIV e estava enveIhecendo. Ou seja, alguém bastante à margem da normativa vigente. Ainda assim, ele, de fato, foi amado, acolhido, cuidado. Com sua individuali- 
dade marcada por um conjunto de elementos que em nossa sociedade são objeto de estigma, ele pôde existir. Não somente sobreviver, mas ter uma existência tão significativa, que, após a sua morte, decidiu que o que restou de si mesmo deveria continuar no lugar que lhe permitiu existir.

Esse é um tipo de sociabilidade também presente no filme $A$ excêntrica família de Antônia. A protagonista acolhe, convive, cuida de muitos "outros”, além de sua linhagem biológica. Outros considerados tão estranhos que a tradução brasileira do filme adjetivou a família de Antônia como "excêntrica", que remete a estranho, diferente, não habitual. Assim são nomeados em nossa cultura todos aqueles que não se enquadram nos modelos hegemônicos.

A família de Antônia se assemelha ao lugar das ONG: um espaço de inclusão, de pertencimento, de aceitação das diferenças. Um espaço no qual o coletivo faz sentido e um sentido que os excêntricos, loucos, monstros, doentes não encontraram em outros espaços da sociedade.

E esse lugar à margem passa também pelas questões de gênero, no caso das ONG AIDS, com a grande presença de homossexuais e, no caso de Antônia, com a desconstrução dos estereótipos do feminino.

Os homossexuais foram precursores na criação de ONG AIDS, na recusa da morte como algo inevitável, da morte anunciada, da morte em vida (Daniel, 1991). Antonia é forte, sexuada, não submetida aos ditames dos destinos tradicionalmente desenhados ao feminino. Dentre tantos exemplos presentes no filme, um que simbolicamente marca esse percurso é a cena em que Antônia recusa o pedido de casamento. ${ }^{3}$

Em síntese: estamos diante de desenhos de vida que resistiram ao preconceito, que resistiram aos modelos hegemônicos, que inventaram novas formas de viver e nos levam a pensar no lugar da amizade na sociedade contemporânea.

Formas de existência que resistem ao biopoder e desenham possibilidades de novos ares para a vida em comunidade. A seguir exploro um pouco mais a que me refiro quando falo de amizade e questiono o lugar central da família (e do que é familiar) como fonte de amparo diante das vicissitudes da existência.

\section{Notas sobre amizade e familia}

A amizade, no dicionário Houaiss, é definida como:
3. Ela, que está sozinha com uma filha no período pósguerra, é pedida em casamento por um homem também sozinho com filhos. 0 casamento poderia ser o destino apropriado ou inevitável diante da situação, mas a protagonista se coloca no lugar de quem pode escolher. E escolhe viver a relação de modo autônomo, seguindo seus tempos e desejos. 
1 sentimento de grande afeição, de simpatia (por alguém não necessariamente unido por parentesco ou relacionamento sexual); 2 reciprocidade de afeto; 3 p.met. aquele que é amigo, companheiro, camarada; ‘ fez dela uma de suas a. prediletas `; 4 relacionamento social (mais us. no pl.); faz amizades facilmente ’; 5 concordância de sentimentos ou posição a respeito de algum fato; acordo, pacto, aliançar tratado de $a$. ।; 6 apego (de alguns animais) pelo homem r cães demonstram $a$. abanando o rabo '; 7infrm. atitude ou gesto de benevolência, de complacência < tratou o bêbedo com a. >; 8ant. estado de concubinato; mancebia; $9 B$ infrm.us. como interlocutório pessoak ei, não vá com tanta pressa, a.! ’.

O dicionário oferece pistas de que a palavra "amizade" pode possuir muitos sentidos. A ideia de afeto entre duas pessoas está presente na amizade; entretanto, neste texto, mais do que a definição do dicionário ou o sentido que atribuímos no senso comum à amizade, estou interessada em estabelecer um diálogo com as reflexões que a filosofia vem tecendo sobre o tema.

Ortega $(2002,2009)^{4}$, um dos estudiosos sobre o tema, sinaliza que a preocupação sociológica e social-filosófica com a amizade é recente, data dos anos 1970. Ainda segundo o autor, diferentes abordagens são tomadas: na perspectiva da literatura anglo-americana, a amizade é concebida com um problema moral e interpretada numa perspectiva kantiana; e, na sociologia, com frequência, é um tema menor, desqualificado. $\mathrm{O}$ autor indica ainda que a temática passou a ser objeto da filosofia francesa:

Uma série de pensadores, entre eles Maurice Blanchot, Michael Foucault, Jacques Derrida, Giles Deleuze, Felix Guattari, Jean Luc Nancy, tem colocado a questão da amizade e da comunidade no centro de sua filosofia, com frequência no contexto de uma tentativa de recuperar o político para a comunidade, de re-pensar, re-construir, o político e a democracia. Ou seja, a amizade seria deslocada da esfera privada, da intimidade, para o mundo a sociabilidade, o público. (ORTEGA, 2009, p.57)

4. Ortega se dedicou ao tema a partir do diálogo com o pensamento de autores como Hanna Arendt, Derrida e, principalmente, Michael Foucault. Escreveu uma trilogia sobre a amizade (Ortega, 1999, 2002, 2009). 0 diálogo com suas ideias influencia muito o olhar que norteia este texto.
É nesse sentido que, nas reflexões que aqui desenvolvo, faço uso do conceito, considerando que a amizade representa: “um exercício do político', um apelo a experimentar formas de sociabili- 
dade e comunidade, a procurar alternativas às formas tradicionais de relacionamento" (ORTEGA, 2009 p. 23-24).

Para Foucault (2004C), a dimensão política está ligada à ética e à estética da existência e também à liberdade: “o que é a ética senão a prática da liberdade? A prática refletida da liberdade?" (p.267).

Foucault (2004a), ao refletir sobre a amizade, sinaliza a importância de pensarmos sobre o modo de vida:

Esta noção de modo de vida me parece importante. Não seria preciso introduzir uma diversificação outra que não aquela devida às classes sociais, às diferenças de profissão, de níveis culturais, uma diversificação que seria também uma forma de relação e que seria o "modo de vida"? [destaque no original] Um modo de vida pode ser partilhado por indivíduos de idade, estatuto e atividade sociais diferentes. Pode dar lugar a relações intensas que não se pareçam com nenhuma daquelas que são institucionalizadas e me parece que um modo de vida pode dar lugar a uma cultura e a uma ética. (p.70)

Ortega (1999), no livro Amizade e estética da existência em Foucault, dá pistas de que as proposições foucaultianas em relação à luta homossexuals e ao seu poder transgressivo não se restringiam necessariamente aos homossexuais ou a uma perspectiva individual, e é possível pensar na expansão dessas reflexões para heterossexuais e grupos minoritários e organizados. Ou seja, o que Foucault pensou a partir de um modo de vida gay pode ser importante para refletirmos sobre o lugar político da amizade na sociedade. Ortega (1999) aponta:

a dimensão ético transgressiva da amizade consiste na recusa das formas impostas de relacionamento e de subjetividade. (p. 170)

0 projeto foucaultiano de uma ética da amizade no contexto de uma possível atualização da estética da existência permite transcender o marco da auto-elaboração individual para se colocar numa dimensão coletiva. A amizade supera a tensão entre o indivíduo e a sociedade mediante a criação de um espaço intersticial (uma subjetivação coletiva) suscetível de considerar tanto necessidades individuais quanto objetivos coletivos e de sublinhar sua interação. (p.171)

5. “A homossexualidade é uma ocasião histórica de reabrir virtualidades relacionais e afetivas, não tanto pelas qualidades intrínsecas do homossexual, mas pela posição de 'enviesado', em qualquer for$\mathrm{ma}$, as linhas diagonais que se podem traçar no tecido social, as quais permitem fazer aparecer essas virtualidades." (Foucault, 2004a, p.71). 
O autor fala da invenção de novas formas de existência, pautadas na amizade e na criação de espaços sociais que sejam menos normativos e busquem veias de fuga do discurso hegemônico. No conceito de amizade é possível contemplar indivíduos e coletividades, e a dimensão política incorpora as subjetividades que desenham escolhas éticas para a própria existência.

Até aqui teci algumas notas sobre amizade, mas é importante entrelaçá-las às reflexões sobre família e observar os desenhos que se formam. Quando pensamos em família, estamos diante de três tarefas. A primeira, já sinalizada na literatura da área, que especificamente aborda esta temática, é a desconstrução do modelo de família nuclear como referência do que seja família. É preciso pensar na pluralidade das famílias ${ }^{6}$.

No exercício de refinamento conceitual da categoria familia, é preciso, contudo, escapar à tentação de adotar modelos universais e generalizantes. Deve-se considerar tal advertência tanto na análise sobre a estrutura e dinâmica da familia contemporânea, como sobre os sentidos e práticas relacionados com saúde-doença-cuidado no contexto familiar. À medida que se afirmar o caráter plural ou polimorfo da familia reafirma-se também a sua complexidade, evidenciando-se a falência de modelos explicativos de pretensão universalista. De entrada, é necessário destacar que o processo de transformação de modelos e padrões familiares revela-se heterogêneo, fragmentado e marcado por ambiguidades, quando comparamos a realidade de diferentes sociedades e/ou grupos sociais. (Trad, 2010, p.29)

A discussão sobre amizade agrega duas dimensões ao debate sobre família. A primeira é questionar a aproximação que se faz do amigo ao familiar. Um dos pontos centrais destacados por Foucault, por Derrida e por autores que trabalharam a partir de suas obras é a relevância de desconstruir a associação do amigo ao familiar. Na retórica do cotidiano, observamos facilmente tal associação: Quando nos referimos a alguém que é um grande amigo, habitualmente dizemos: "mais do que um amigo, ele é um irmão".

Entretanto, nem sempre atentamos às armadilhas dessa discursividade e às im-

6. Ver, por exemplo: Acosta \& Vitale, 2003; Carvalho, 2002; Meyer, Klein, \& Fernandes, 2012; Sarti, 2003 , 2004 . plicações semânticas que aí estão engendradas $A$ esse respeito, Gomes e Silva Júnior (2008) sinalizam: 
0 clássico discurso de amizade caracteriza-se por uma semântica que qualifica o vinculo de amizade como vínculo de familiaridade ou parentesco, associando o amigo à figura do irmão. 0 lar (oikeiotès) encontra-se dentro do locus semântico de philia - que é resumido como "em volta da casa", privilegiando valores de familiaridade, proximidade, igualdade de gostos e opiniões, afinidade, conveniência, fraternidade. (p.268)

A segunda questão é a própria ideia de que a família é o elemento nuclear da sociedade, porque é a família que é responsável pelo cuidado das pessoas. Diante de pessoas doentes ou desamparadas, habitualmente perguntamos: "Você tem família?”. Ou então pensamos: Onde está a família, que não cuida dele (a)?

Muitas vezes mantemos esse parâmetro, mesmo sabendo que, em vários casos, um conjunto de relações delicadas e impossibilidades de diferentes ordens (materiais, afetivas, sociais) impede a família de oferecer o cuidado de que o sujeito necessita (ou que imaginamos que necessite).

Por outro lado, na experiência da ONG, várias vezes ouvi as pessoas dizendo: “Aqui é minha família”. Como membro do grupo, tenho vários amigos que considero da minha família. Entretanto, eis a questão: por que algo significativo tem que ser família? Por que, no filme, os amigos que se unem a Antônia, apesar de adjetivados como excêntricos, passam a compor a família? Justamente porque parece que a família é o lugar que cria $o$ sentido na teia do social.

Penso que podemos rever essa perspectiva que, ao mesmo tempo, cria um lugar de proteção aos indivíduos e enfraquece o espaço público como um contexto que também é responsável pelas pessoas. Somos responsáveis por quem na sociedade? "Pelos nossos amigos e familiares" é a resposta mais imediata. Contudo, por que não somos responsáveis pelas pessoas que não estão encaixadas nessas duas categorias (amigos e familiares)?

Para elas ainda existe a fraternidade, manifestada com frequência, como ajuda caridosa. Essa ajuda, muitas vezes, é bem-vinda; contudo, novamente temos a questão da assimilação do outro ao irmão7. Ao associarmos o amigo ao irmão, a fraternidade ao irmão e o irmão a nós mesmos, criamos uma sociedade na qual os indivíduos tendem a valorizar aquilo que se aproxima de si, aquilo que the é familiar. A diferença fica estabelecida como uma alteridade não desejada, e isso enfraquece a dimensão política.

A noção de amizade debatida na perspectiva

7. Segundo o dicionário Houaiss, a etimologia da palavra remete ao parentesco, à irmandade: "lat. fratern $t s$, tis "parentesco entre irmãos, fraternidade”. 
foucaultiana pede justamente o movimento contrário a essa assimilação da diferença ao conhecido (amigo/irmão).

Dessa maneira, o que se enfoca não é o apego a formas de identidade com características em comum, mas sim um esforço para a compreensão e aceitação do outro como diferença inquietante.... Não se deve buscar encontrar no amigo um reforço para sua identidade, mas, pelo contrário, material para transformação e criação do Si. (Cardoso Jr \& Naldinho, 2009, p.51)

É importante, porém, não entender de modo binário o que aqui debato ao redor do conceito de família (e de familiar), por exemplo, tomando a família como "vilã" da sociedade, ou propondo a eliminação de todos os tipos de família. Uso aqui as palavras de Ortega (2009) que tão bem expressam essa questão: “Não se trata de negar a família como instituição, mas de combater o monopólio que ela exerce sobre nosso imaginário emocional, de deixar de pensar as relações de amizade em imagens familiares, para poder reinventar a amizade" (p.115).

Meu interesse, ao desenhar tais problematizações, caminha muito mais na direção de refletir sobre como lidamos com as diferenças, como rompemos com um esvaziamento do espaço público quando a homogeneização dos sujeitos domina a esfera política. Somos subjetivados por modos de vida que ganham estatuto de normalidade e, por vários motivos ${ }^{8}$, agarramos modos de existência conhecidos e não adentramos novas possibilidades e invenções.

Neste processo de busca de novas possibilidades de existência, seria ingênuo pensar que as ONG que compõem a luta contra AIDS não são normativas e não estão institucionalizadas. Para desfazer-nos dessa ilusão, podemos pensar na briga por espaços de representações, projetos e identidades. E observaremos que nem sempre vigora o que aqui denominamos de amizade.

Tampouco Antônia escapa de algumas capturas, ou seja, ela não fica totalmente fora dos ditames de alguns padrões tidos como verdade ou como noções do senso

8. Talvez, sem juízo de valor, possamos indagar: medo? Acomodação? Falta de horizontes?

9. Não há problema no desejo de um filho biológico, mas não observamos no filme a problematização sobre o domínio da dimensão biológica como constituinte da maternidade. comum: por exemplo, Danielle busca um filho biológico` e busca também um homem para procriar. No filme, vemos ainda que os intelectuais são solitários, isolados, problemáticos, como a neta e Dedo Torto. 
Na perspectiva teórica que adotamos, não há um “lugar fora”, protegido dos processos de subjetivação da cultura. Estamos todos "dentro". Dentro das capturas e das possibilidades de resistências. 0 trabalho ético-estético da existência é justamente a reflexão permanente, para observar as trilhas que nos enredam ou se apresentam como linhas de fuga. Um trabalho sobre si que constantemente nos leva a fugir do fascismo.

E não somente o fascismo histórico de Hitler e de Mussolini - que tão bem souberam mobilizar e utilizar o desejo das massas -, mas o fascismo que está em nós todos, que martela nossos espíritos e nossas condutas cotidianas, o fascismo que nos faz amar o poder, desejar esta coisa que nos domina e nos explora. (Foucault, 2004 b, p.5)

Contudo, não estamos sem saída. Antônia e T. efetivamente mostram novas possibilidades. Um sopro, uma invenção, uma resistência. Há algo nessas histórias que nem sempre nos propomos a parar para examinar com cuidado. Com frequência, ficamos presos ao conhecido. Não se trata de inventar novas formas de existência que se tornariam universais e, portanto, novamente hegemônicas, nem se trata de deixar de reconhecer as capturas que existem até mesmo nas novas possibilidades. Trata-se, porém, de reconhecer que é possível viver de outro modo. E, principalmente, a experiência de T. (que extrapola as telas de cinema) é que nos revela esse fato.

Em síntese, o que estou tentando dizer é que a escolha de T. convidou-me a pensar: o que estamos inventando, afinal, nesta resistência coletiva à epidemia da AIDS? Certamente apoio, exercício de direitos e um pouco mais de qualidade de vida para as pessoas que vivem com HIV/AIDS. Mas seria somente isso?

Viver a história e, ao mesmo tempo, pensar-se é um exercício difícil. Talvez agora, após 30 anos de epidemia, possamos examinar com um pouco mais de cuidado essas ideias.

A resposta social à epidemia da AIDS pode ser pensada e analisada muito além dos efeitos que tem diante da própria epidemia. Algumas experiências de convivência, cuidado e socialização dão pistas de que é possível visualizar novas possibilidades de vida.

Será que nas organizações sociais não estão sendo engendradas novas formas de existência? Alguns respiros para a falta de oxigênio da hegemonia discriminatória? Ao defendermos pessoas que estão condenadas ao limbo, à ausência de direitos, à 
morte, não estamos tecendo uma resistência que desenha novas estéticas da existência?

Se nos lembrarmos de tudo aquilo que de visceral representamos, principalmente o combate ao racismo, com suas marcas de estigma e discriminação; a liberdade de existir como o sujeito que se queira (ou se possa) ser; e a criação de um novo modo de vida, em que sujeitos possam se sentir pertencendo a coletivos que para eles façam sentido, talvez possamos reiterar nosso compromisso de produzir, no microcotidiano de nossas ações, a construção da amizade.

Talvez, como movimento e como sujeitos, devamos pensar em todas essas questões e refletir sobre os sentidos (e/ou os sem sentidos) da nossa vida-obra de arte. Aquela que desenhamos - ou que poderíamos desenhar.

Com falhas, desencontros, fragilidades e ainda capturas nos modelos hegemônicos de sexualidade e família, temos conseguido fazer parte da história do nosso país, produzindo episódios que vão desde a quebra de patentes - o que significa dizer que a vida é mais importante que o capital - até um jardim que faça sentido.

Aqui cabe pensar nas palavras de Loponte (2009): “A amizade, esse doce sabor do outro, daquele que nos completa, ou que se diferencia de nós, nos faz mais vivos, mais parte desse mundo. Por que não reinventar a política mediante essas relações, que nos reinventam a cada dia?” (p.922)

\section{Considerações finais}

As perguntas mobilizam movimentos, são molas propulsoras de voos em busca de novos horizontes para as inquietudes que nos interpelam. Quais os lugares dos conceitos de família e amizade na sociedade contemporânea? Como as concepções hegemônicas desses conceitos nos subjetivam? E como nos subjetivam, como pessoas que têm famílias e amigos e também como profissionais da área da saúde, da educação e da seguridade social?.

É a família o lugar social para cuidar do desamparo? O único lugar social seguro? E quem dá suporte para a família, que tudo deveria suportar? Na família só cabe o familiar?

Os estranhos, os excêntricos, são peças que não se encaixam nas famílias, nas sociedades e nas amizades? Ou somente são possíveis quando nomeados, regulados e devidamente classificados com diagnósticos, apelidos que nomeiam sua estranheza? 
Quem não tem pai, mãe, filhos(as), irmãos(as), tios(as), companheiro(a), não tem família? Sem família não temos "ninguém no mundo"?

Não vou responder a essas questões, mas espero ter percorrido um caminho que leve à reflexão, principalmente à reflexão a respeito de como a amizade pode ser relevante para a política, para o espaço público, para nossas vidas, para a poesia em nossas vidas.

A morte é tida como ponto final, mas poderia ser concebida como ponto de interrogação. Questiono “os universais” no desenho dos conceitos, mas, por ora, sermos mortais é a única dimensão que nos une. E nós, que temos apego à ideia do familiar, diante do mistério e da dor, preferimos esquecer esse detalhe e, ao invés de nos unirmos, guerreamos por tantas coisas absolutamente sem sentido.

A discursividade a respeito da fraternidade resulta ora em práticas fraternas, ora em práticas fraticidas. Basta olharmos para as relações de trabalho, para a competitividade, para a ideia de ser “melhor que o outro", mais reconhecido, mais, mais...

Qual o sentido disso, diante da morte, da vulnerabilidade humana? Não se trata de criar uma falsa harmonia nas teias do social, mas de refletir a respeito de como desenhamos as disputas em sociedades capitalistas e ditas democráticas e supostamente abertas ao lema iluminista da liberdade, igualdade e fraternidade.

No filme e na vida real, a morte como inevitabilidade está presente, e há o registro do que se fez com a vida. E a vida foi obra de arte, não foi vazia; desenhou sentido numa ética e numa estética da existência, com base no que podemos pensar como amizade. As pessoas partilharam o existir com os "outros" e produziram uma vida e uma morte encharcadas de sentido.

Para finalizar, lembro a tradição de alguns povos de bordar toda sua história em pequenos tapetes, inclusive de bordar jardins nos tapetes. Desse modo, podemos supor que jardins tão pequenos como tapetes podem significar muito.

E é preciso que, ao realizarmos nossas pequenas/grandes tarefas cotidianas, possamos nos lembrar das palavras de Foucault (200l): “O jardim é a menor parcela do mundo e é também a totalidade do mundo" (p. 418).

Antônia e T. escolheram seus jardins, bordaram seus tapetes. Vemos suas vidas como obras de arte a nos lembrar de interpelar-nos: E nós? Como bordamos nossa existência? 


\section{Referências bibliográficas}

Acosta, A. R., \& Vitale, M. A. F. (Org.). (2003). Família: laços, redes e políticas públicas. São Paulo: IEE-PUCSP.

Ariès, P. (2003). História da morte no Ocidente. Rio de Janeiro: Ediouro.

Bromberg, M. H. P. F., Kovács, M. J., Carvalho, M. M. M. J., \& Carvalho, V. A. (1996). Vida e morte: laços da existência. São Paulo: Casa do Psicólogo.

Cardoso Jr., H. R., \& Naldinho, T. C. (2009, janeiro/abril). A amizade para Foucault: resistências criativas face ao biopoder. Fractal: Revista de Psicologia, 21(1), 43-56.

Carvalho, M. C. B. (Org.). (2002). A família contemporânea em debate. São Paulo: EDUC; Cortez.

Castro, E. (2009). Vocabulário de Foucault (I. M. Xavier, trad., A. Veiga-Neto, \& W. O. Kohan, rev.) Belo Horizonte: Autêntica.

Daniel, H. (1991). Vida antes da morte. Rio de Janeiro: Escritório e Tipografia Jaboti.

Elias, N. (2001). A solidão dos moribundos. Rio de Janeiro: Zahar.

Foucault, M. (1999). Em defesa da sociedade: curso no Collège de France. (M. E. Galvão, trad., 382 pp.). São Paulo: Martins Fontes.

Foucault, M. (2001). Outros espaços (conferência). In Foucault, M., Ditos e escritos III. Estética: literatura e pintura, música e cinema (M. B. da Motta, org. e sel. de textos, I. A. D. Barbosa, trad., pp. 411-422). Rio de Janeiro: Forense Universitária.

Foucault, M. (2003). História da sexualidade 1: a vontade de saber (M. T. C. Albuquerque, \& J. A. G. Albuquerque, trads., 15a ed., 152 pp.). Rio de Janeiro: Graal.

Foucault, M. (2004a). Da amizade como modo de vida (W. F. Nascimento, trad., entrevista de Michel Foucault a R. de Ceccaty, J. Danet, \& J. le Bitoux, publicada no jornal Gai Pied, (25), abril de 1981, pp. 38-39). In Michel Foucault - por uma vida não fascista. Obra compilada pelo Coletivo Sabotagem.

Foucault, M. (2004b). Introdução à vida não fascista. Prefácio. In G. Deleuze, \& F. Guattari, Anti-Oedipus: capitalism and schizophrenia (W. F. do Nascimento, trad., pp. 11-14). New York: Viking Press, 1977. In Michel Foucault - por uma vida não fascista. Obra compilada pelo Coletivo Sabotagem.

Foucault, M. (2004C). A ética do cuidado de si como prática da liberdade. In M. Foucault, Ditos e escritos V. Ética, sexualidade, política (M. B. da Motta, org. e sel. de textos, E. Monteiro, I. A. D. Barbosa, trad., pp.264-287). Rio de Janeiro: Forense Universitária.

Giacoia Jr, O. (2005). A visão da morte ao longo do tempo. Medicina, 38(1), 13-19. 
Gomes, L. G. N., \& Silva Júnior, N. (2008, abril/junho). Implicações políticas da semântica familiarista nos discursos de amizade contemporâneos. Psicologia em Estudo, 13(2), 267-275.

Houaiss, A. (2015). Grande dicionário Houaiss da língua portuguesa. Retirado em 14 de abril de 2015, de http://houaiss.uol.com.br/

Kóvacs, M. J. (Coord.). (1992). Morte e desenvolvimento humano. São Paulo: Casa do Psicólogo.

Kübler- Ross, E. (1998). Sobre a morte e o morrer. São Paulo: Martins Fontes.

Larrosa Bondía, J. (2002, janeiro/fevereiro/março/abril). Notas sobre a experiência e o saber de experiência. Revista Brasileira de Educação, 19, 20-28.

Loponte, L. G. (2009, setembro/dezembro). Amizades: o doce sabor dos outros na docência. Cadernos de Pesquisa, 39(138), 919-938.

Meyer, D., Klein, K., \& Fernandes, L. P. (2012, maio-agosto). Noções de família em políticas de 'inclusão social' no Brasil contemporâneo. Estudos Feministas, 20(2), 433-449.

Ortega, F. (1999). Amizade e estética da existência em Foucault. Rio de Janeiro: Graal.

Ortega, F. (2002). Genealogias da amizade. São Paulo: Iluminuras.

Ortega, F. (2009). Para uma política da amizade: Arendt, Derrida, Foucault. Rio de Janeiro: Sinergia; Relume Dumará.

Sarti, C. A. (2003). A família como espelho: um estudo sobre a moral dos pobres (2a ed. rev.) São Paulo: Cortez.

Sarti, C. A. (2004). A família como ordem simbólica. Psicologia USP, 15(3), 11-28.

Teixeira, P. R., Paiva, V., \& Shimma, E. (2000). Tá difícil de engolir? Experiências de adesão ao tratamento anti-retroviral em São Paulo. São Paulo: Nepaids.

Trad, L. A. B. (2010). A família e suas mutações: subsídios ao campo da saúde. In Trad, L. A. B. (Org.), Família contemporânea e saúde - significados, práticas e políticas públicas. Rio de Janeiro: Editora FIOCRUZ.

Submetido à avaliação em 31 de maio de 2015; aprovado para publicação em 21 de agosto de 2015 . 
